\title{
COOLING INTENSITY OF INVERSE SOLUBILITY \\ POLYALKYLENE GLYKOL POLYMERS AND SOME RESULTS OF INVESTIGATIONS FOCUSED ON MINIMIZING DISTORTION OF METAL COMPONENTS
}

\author{
Nikolai Kobasko \\ Intensive Technologies Ltd \\ 68/1 Peremohy ave., Kyiv, Ukraine, 03113 \\ nkobasko@gmail.com
}

\begin{abstract}
Poly(Alkylene Glycol) polymers of inverse solubility (PAG) provide ideal uniform cooling for minimizing distortion and preventing crack formation during hardening machine components and tools. However, in spite of ideal cooling, from time to time, a big distortion takes place during hardening process. A reason for a big distortion development during hardening in PAG solutions is explained and an idea how to fix the problem is suggested. It is shown that at the end of cooling coating can be locally dissolved by a cold water flow creating local open area where martensite transformation starts first. Due to greater specific volume of martensite, it creates a big distortion. To solve the problem, one should interrupt cooling process or stop agitation before insulating coating is dissolved. To perform correctly proposed technology, cooling intensity of inverse solubility PAG polymers of 1-20\% were investigated on the basis of use of regular thermal condition theory. As a result, dimensionless effective numbers Kn were obtained for recipes development. A technique for solving the problem is proposed by author. Examples of calculations are provided.

Keywords: PAG polymers, effective number Kn, polymeric layer, local dissolving, local tranformation, low PAG concentration, intensity, distortion, reduction, recipes, technique, benefits.
\end{abstract}

\section{Introduction}

The molecular formula for PAG is [1-3]:<smiles>CC(COCCO)O[Hg]</smiles>

High molecular weight PAG is completely soluble in water at room temperature. PAG also exhibits a unique property in which it has inverse solubility as temperature increases in water. As the temperature rises, the PAG precipitates out of the solution and deposits on the surface of the part. At temperatures above $74^{\circ} \mathrm{C}\left(165^{\circ} \mathrm{F}\right)$, the polymer separates from water as an insoluble phase. The deposited layer serves as an insulator which, in turn, governs the rate of heat extraction from the quenched part. This layer decreases initial heat flux density since it thermal conductivity is within $0.1-0.145 \mathrm{~W} / \mathrm{mK}[2,3]$. As the temperature of the part decreases, the polymer dissolves back into the aqueous solution. Quenchant concentration, quenchant temperature and quenchant agitation govern the rate of heat transfer. Until now, there is no method available for transition from standard probe to real steel parts in order to develop recipes improving srength of materials and decreasing distortion. Results of investigations in this area are discussed in this short communication.

\section{Methods used for evaluation cooling intensity of polymers}

2. 1. Standard Inconel 600 probe used for investigation of PAG polymers

At present time polymer quenchants are manufactured and further investigated by The Dow Chemical Company $[2,3]$. Each type of PAG water solution with corrosion inhibitor is nonflammable polymeric quenchant. The standardized probes for evaluation of cooling intensity of quenchants are discussed in $[4,5]$. Test methods based on ASTM Standards D6200-01, D6482-99, and D6649-00 for determining the cooling characteristics of quenchants by cooling of probes made from Inconel 600 material are widely used in practice $[4,5]$. The chemical composition of Inconel 600 is: $72 \%$ nickel; $14-17 \%$ chromium; $6-10 \%$ iron; $0.15 \%$ carbon; $0.5 \%$ copper; and $0.5 \%$ silicon. The diameter of the probe is $12.5 \mathrm{~mm}$ and its length is $60 \mathrm{~mm}$. Unfortunately, cooling 
curves obtained by standard probe are not suitable for evaluation of real heat transfer coefficients during transient nucleate boiling processes [6]. The standard Inconel 600 probe was developed to check and maintain stability of quenchants and can provide only effective heat transfer coefficients [7, 8].

\section{2. Investigation cooling intensity of PAG polymers based on regular thermal condi-} tion theory

Cooling intensity of PAG polymers was evaluated using generalized equation for cooling rate calculation $[9,10]$ :

$$
\mathrm{v}=\frac{\mathrm{aKn}}{\mathrm{K}}\left(\mathrm{T}-\mathrm{T}_{\mathrm{m}}\right)
$$

where $\mathrm{v}$ - cooling rate in ${ }^{\circ} \mathrm{C} / \mathrm{s} ; \mathrm{a}$ - average thermal diffusivity of a material in $\mathrm{m}^{2} / \mathrm{s}$; $\mathrm{Kn}$ - dimensionless Kondratjev number; $\mathrm{K}$ - Konratjev form factor in $\mathrm{m}^{2}$ [9]; $\mathrm{T}$ - current temperature in ${ }^{\circ} \mathrm{C}$; $\mathrm{T}_{\mathrm{m}}$ - temperature of quenchant in ${ }^{\circ} \mathrm{C}$. Dimensionless number $\mathrm{Kn}$ changes within 0 and 1 when heat transfer coefficient or generalized Biot number changes from 0 to infinity [10].

Experiments of author and many experimental data on cooling rates versus time provided in the Internet and published in books and scientific journal were used for calculating dimensinless number Kn for polymer solutions versus concebtration and size of probes [11, 12]. The summaring results are provided in Fig. 1.

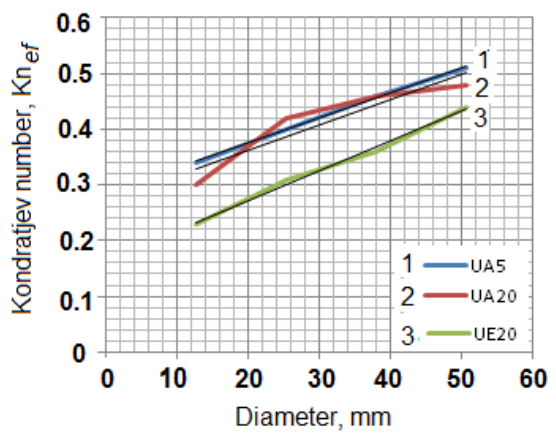

Fig. 1. Effective numbers Kn vs. diameter of cylindrical samples made of AISI 4140 steel during their queching in water PAG solutions of different concentration at $43{ }^{\circ} \mathrm{C}$ and agitation:

1 - UCON A of $5 \%$ water solution agitated with $0.254 \mathrm{~m} / \mathrm{s} ; 2-\mathrm{UCON}$ A of $20 \%$ water solution agitated with $0.508 \mathrm{~m} / \mathrm{s} ; 3$ UCON E f $20 \%$ water solution agitated with $0.508 \mathrm{~m} / \mathrm{s}$

Similar results were obtained for still and agitated water salt solutions of optimal concentration (Fig. 2) [7].

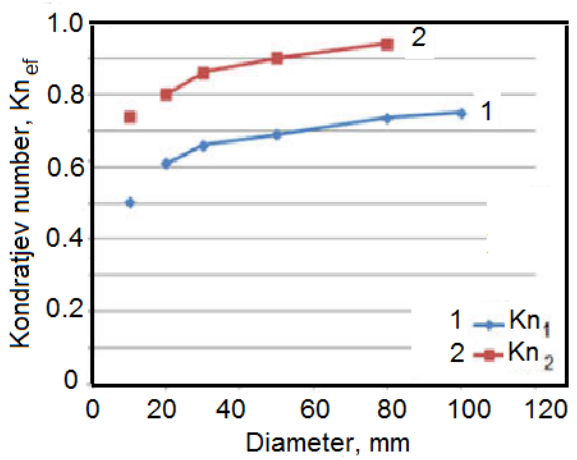

Fig. 2. Effective Kondratjev number Kn versus diameter of cylindrical probes made of AISI 304 steel when quenching in $8 \%$ water solution of $\mathrm{NaNO}_{3}$ at $20{ }^{\circ} \mathrm{C}$ : 1 - quenching in still solution; 2 - quenching in solution flow $1.5 \mathrm{~m} / \mathrm{s}$ 
Water solutions have higher dimensionless Kn number because no insulating polymeric layer on the surface of metal during quenching in water salt solutions (Fig. 1, 2). Let's note that shape of steel part effect insignificantly the effective value of $\mathrm{Kn}[10]$.

\section{Effect of insulating layer on temperature field in coated metal}

For investigating effect of insulating coating on temperature distribution in a coated metal, namely in long cylinder, the next mathematical model was analyzed:

$$
\begin{gathered}
\frac{\partial \mathrm{T}_{1}}{\partial \tau}=\mathrm{a}_{1}\left(\frac{\partial^{2} \mathrm{~T}_{1}}{\partial \mathrm{r}^{2}}+\frac{1}{\mathrm{r}} \frac{\partial \mathrm{T}_{1}}{\partial \mathrm{r}}\right)\left(\tau>0 ; \quad 0 \leq \mathrm{r} \leq \mathrm{R}_{1}\right) ; \\
\frac{\partial \mathrm{T}_{2}}{\partial \tau}=\mathrm{a}_{2} \frac{\partial^{2} \mathrm{~T}_{2}}{\partial \mathrm{r}^{2}}\left(\mathrm{R}_{1} \leq \mathrm{r} \leq \mathrm{R}_{2}\right) ; \\
\mathrm{T}_{1}\left(\mathrm{R}_{1}, \tau\right)=\mathrm{T}_{2}\left(\mathrm{R}_{1}, \tau\right) ; \lambda_{1} \frac{\mathrm{T}_{1}\left(\mathrm{R}_{1}, \tau\right)}{\partial \mathrm{r}}=\lambda_{2} \frac{\mathrm{T}_{2}\left(\mathrm{R}_{1}, \tau\right)}{\partial \mathrm{r}} ; \\
\lambda_{2} \frac{\mathrm{T}_{2}\left(\mathrm{R}_{2}, \tau\right)}{\partial \mathrm{r}}+\alpha\left[\mathrm{T}_{2}\left(\mathrm{R}_{2}, \tau\right)-\mathrm{T}_{\mathrm{c}}\right]=0 ; \\
\mathrm{T}_{1}(0, \tau)=\mathrm{T}_{2}(0, \tau)=\mathrm{T}_{0} .
\end{gathered}
$$

Analytical solution for (2)-(6) is known and can be presented as ((7), [13])

$$
\frac{T_{1}(r, \tau)-T_{c}}{T_{o}-T_{c}}=\sum_{n=1}^{\infty} A_{n} J_{0}\left(\mu_{n} r / R_{1}\right) \exp \left(-\mu_{n}^{2} F o\right)
$$

which is true for insulated metal.

Temperature distribution within the insulating layer is calculated by Eq; (8):

$$
\begin{gathered}
\frac{\mathrm{T}_{2}(\mathrm{r}, \tau)-\mathrm{T}_{\mathrm{c}}}{\mathrm{T}_{\mathrm{o}}-\mathrm{T}_{\mathrm{c}}}=\sum_{\mathrm{n}=1}^{\infty} \mathrm{A}_{\mathrm{n}}\left\{\mathrm{J}_{0}\left(\mu_{\mathrm{n}}\right) \cos \left[\mu_{\mathrm{n}} \mathrm{K}_{\mathrm{a}}{ }^{1 / 2}\left(\mathrm{r} / \mathrm{R}_{1}-1\right)\right]-\right. \\
\left.-\mathrm{K}_{\mathrm{a}} \mathrm{J}_{1}\left(\mu_{\mathrm{n}}\right) \sin \left[\mu_{\mathrm{n}} \mathrm{K}_{\mathrm{a}}{ }^{1 / 2}\left(\mathrm{r} / \mathrm{R}_{1}-1\right)\right]\right\} \exp \left(-\mu_{\mathrm{n}}{ }^{2} \mathrm{Fo}\right),
\end{gathered}
$$

where $T_{1}(r, \tau)$ - temperature distribution in metallic section; $T_{2}(r, \tau)$ - temperature distribution in a coating; $A_{n}$ temperature amplitudes; $J_{0}\left(\mu_{n}\right)$ the first kind of Bessel function of zero order; $J_{1}\left(\mu_{n}\right)$ the first kind of Bessel function of first order; $\mu_{n}$ - roots of characteristics equation [13]; $\mathrm{K}_{\mathrm{a}}=\frac{\mathrm{a}_{1}}{\mathrm{a}_{2}} ; \mathrm{a}_{1}$ - thermal diffusivity of a metal in $\mathrm{m}^{2} / \mathrm{s} ; \mathrm{a}_{2}$ - thermal diffusivity of a coating in $\mathrm{m}^{2} / \mathrm{s}$; Fo - dimensionless Fourier number.

If thermal conductivity of coating is very low, effective heat transfer coefficient (HTC) on the surface created by radius $\mathrm{R}_{1}$ is very low as well. Taking into account universal correlation of the regular thermal condition theory [10], one can analyze temperature distribution in a coated metal, i. e.:

$$
\psi=\frac{\overline{\mathrm{T}}_{\mathrm{sf}}-\mathrm{T}_{\mathrm{c}}}{\overline{\mathrm{T}}_{\mathrm{V}}-\mathrm{T}_{\mathrm{c}}}=\frac{1}{\sqrt{\mathrm{Bi}_{\mathrm{V}}{ }^{2}+1.437 \mathrm{Bi}_{\mathrm{V}}+1}} .
$$


When generalized Biot number $\mathrm{Bi}_{\mathrm{V}} \rightarrow 0$, the ratio $\frac{\overline{\mathrm{T}}_{\mathrm{sf}}-\mathrm{T}_{\mathrm{c}}}{\overline{\mathrm{T}}_{\mathrm{V}}-\mathrm{T}_{\mathrm{c}}} \rightarrow 1$. It means that $\overline{\mathrm{T}}_{\mathrm{sf}} \approx \overline{\mathrm{T}}_{\mathrm{V}}$. Here $\bar{T}_{\mathrm{sf}}$ - average surface temperature created by radius $\mathrm{R}_{1}($ Fig. $\mathbf{5}, \boldsymbol{a})$; $\overline{\mathrm{T}}_{\mathrm{V}}$ - average volume temperature. Exact profile of temperature distribution in metal can be calculated using solution (7). In this particular case $T_{c}=T_{s}, T_{s}$ is saturation temperature. On the other hand, on the surface created by radius $\mathrm{R}_{2}$, generalized Biot number $\mathrm{Bi}_{\mathrm{V}} \rightarrow \infty$ because during nucleate boiling process HTC reaches $200,000 \mathrm{~W} / \mathrm{m}^{2} \mathrm{~K}$ and more [10]. It means that ratio $\frac{\overline{\mathrm{T}}_{\mathrm{sf}}-\mathrm{T}_{\mathrm{c}}}{\overline{\mathrm{T}}_{\mathrm{V}}-\mathrm{T}_{\mathrm{c}}} \rightarrow 0$ and $\overline{\mathrm{T}}_{\mathrm{sf}} \rightarrow \overline{\mathrm{T}}_{\mathrm{s}}$. Exact profile of temperature distribution in the insulating layer can be calculated using solution (8). Thus, insulating layer increases surface temperature of metallic sample that can compete with the quenching under pressure (Fig. 3) [10].

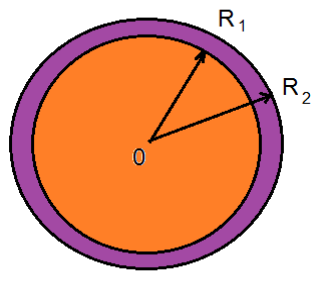

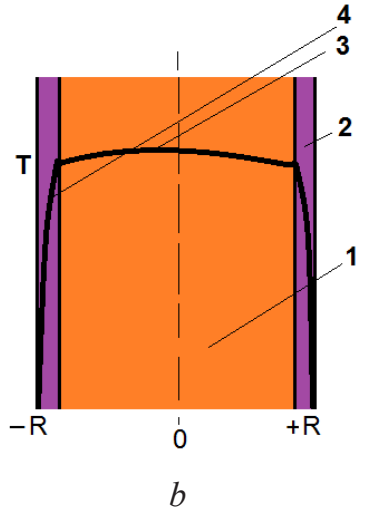

Fig. 3. Section of a coated cylindrical probe and typical temperature distribution during quenching in polymer water solution of inverse solubility: $a$ - section of a cylinder; $b$ - temperature distribution in cylinder; 1 - heated metal, 2 - coating, 3 - temperature gradient in metal, 4 - temperature gradient in polymeric surface layer

The possibility of delaying of martensite transformation combined with accelerated cooling in the inverse solubility polymers is used for implementation of the new patented technologies [14] which include:

- performing two steps quenching with cryogenic treatment on the second step to provide super-strengthening of material and increase its wear resistance [15];

- use for austempering process to obtain nanobainitic microstructure [16-18];

- performing low temperature thermomechanical treatment to obtain high strength and ductility of a material [10].

These ideas will be further developed and discussed in the future.

\section{Why does a big distortion and crack formation during hardening in PAG solutions some- times takes place?}

Ideal cooling in PAG solution is created by insulating layer that can govern effectively quenching processes. However, insulating layer is dissolved when surface temperature drops below $74{ }^{\circ} \mathrm{C}$. Nobody could imagine that this fact is critical and can lead to big distortion and crack formation during quenching. During batch cooling steel parts at the bottom of load are cooled locally by water flow that creates local dissolving of polymeric layer (Fig. 4). At this dissolving areas martensite transformation starts first while in other areas martensitic transformation is delayed due to reason considered above. These local non-uniform martensitic transformations eliminate completely all benefits of PAG inverse solubility polymers. The problems concerning non-uniformity of cooling were considered by authors $[19,20]$.

To solve this unpleasant problem, the dissolving of insulating layer must be protected at the end of hardening process by developing correct recipes of cooling. Unfortunately, heat treating industry uses only cooling curves and cooling rates of standard probe that cannot allow engineers 
performing correct calculations. To fix situation, a simple method of calculation is proposed on the basis of regular thermal condition theory $[9,10]$ and examples of calculation for complicated steel parts are provided below.

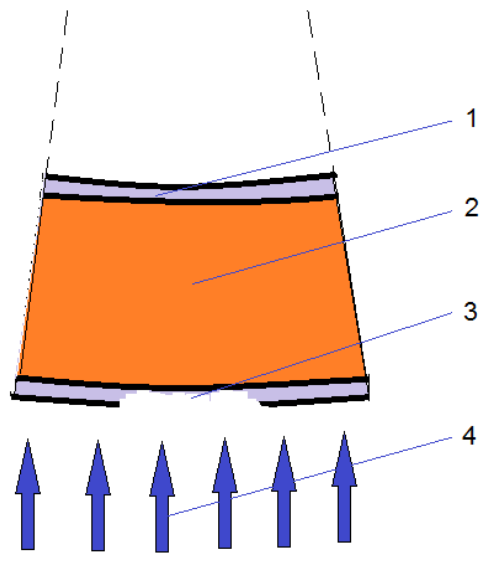

Fig. 4. A scheme explaining why a big distortion takes place during quenching in water PAG polymers solutions: 1 - polymer coating; 2 - quenched steel part; 3 - locally dissolved by water flow polymer coating; 4 - water flow

\section{Examples of recipes calculations}

Cooling time calculation of a core of any shape of steel part can be performed using generalized equation (10), [10]:

$$
\tau=\left[\frac{\mathrm{kBi}_{\mathrm{V}}}{2.095+3.867 \mathrm{Bi}_{\mathrm{V}}}+\ln \left(\frac{\mathrm{T}_{0}-\mathrm{T}_{\mathrm{m}}}{\mathrm{T}-\mathrm{T}_{\mathrm{m}}}\right)\right] \frac{\mathrm{K}}{\mathrm{aKn}} .
$$

\section{Example 1}

Shafts $30 \mathrm{~mm}$ in diameter made of AISI 4140 steel are quenched in batches from $850{ }^{\circ} \mathrm{C}$ in $20 \%$ water polymer $\mathrm{UCON}^{\mathrm{TM}} \mathrm{E}$ Quenchant at $30^{\circ} \mathrm{C}$. Calculate cooling time when core temperature of shaft approaches $350{ }^{\circ} \mathrm{C}$. Form factor $\mathrm{K}$ for long shaft is calculated from equation $\mathrm{K}=\mathrm{R}^{2} / 5.783=$ $=38.9 \times 10^{-6} \mathrm{~m}^{2}$. Average thermal diffusivity of super-cooled austenite is equal to $5.5 \times 10^{-6} \mathrm{~m}^{2} / \mathrm{s}$. Dimensionless number Kn for $\mathrm{UCON}^{\mathrm{TM}} \mathrm{E}$ Quenchant is evaluated from Fig. 1 and is equal to 0.327 and generalized Biot number $\mathrm{Bi}_{\mathrm{V}}$, according to [10] 0.45. Cooling time is calculated using Eq. (10):

$$
\tau=\left[0.235+\ln \left(\frac{850^{\circ} \mathrm{C}-30^{\circ} \mathrm{C}}{350^{\circ} \mathrm{C}-30^{\circ} \mathrm{C}}\right)\right] \frac{38.9 \times 10^{-6} \mathrm{~m}^{2}}{5.5 \times 10^{-6} \mathrm{~m}^{2} / \mathrm{s} \times 0.327}=25.4 \mathrm{sec}
$$

After 25 seconds of cooling agitation in quench tank was stopped and as a result distortion satisfied requirements.

Example 2

Large plugs made of AISI 5140 steel (Fig. 5) are batch quenched from $850{ }^{\circ} \mathrm{C}$ in $1 \%$ water agitated PAG solution at $27{ }^{\circ} \mathrm{C}$. Calculate cooling time when temperature at area $\mathrm{C}$ reaches $400{ }^{\circ} \mathrm{C}$. Dimensionless number $\mathrm{Kn}$ for agitated water solution is 0.8 . Average thermal diffusivity of material is $5.36 \times 10^{-6} \mathrm{~m}^{2} / \mathrm{s}$. Form factor $\mathrm{K}$ for plug is $608 \times 10^{-6} \mathrm{~m}^{2}$.

Using Eq. (10), one can calculate required cooling time for plug

$$
\tau=\left[0.48+\ln \left(\frac{850^{\circ} \mathrm{C}-27^{\circ} \mathrm{C}}{400^{\circ} \mathrm{C}-27^{\circ} \mathrm{C}}\right)\right] \frac{608 \times 10^{-6} \mathrm{~m}^{2}}{5.36 \times 10^{-6} \mathrm{~m}^{2} / \mathrm{s} \times 0.8}=180 \mathrm{sec} .
$$


At a time 180 seconds agitation of solution was turned off and cooling of plug was continued to bath temperature.

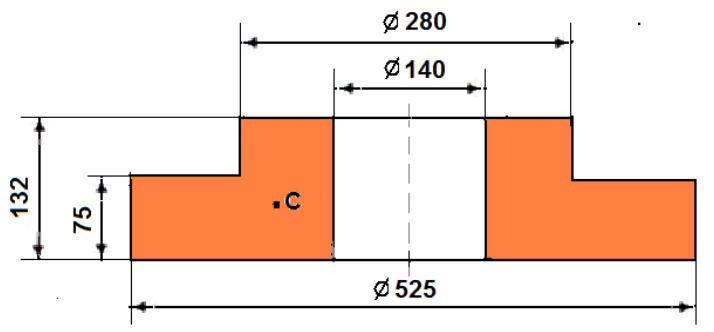

Fig. 5. Drawing of a plug made of high quality alloy steels and used in energy manufacturing stations

\section{Discussion}

Inverse solubility of PAG polymers, used as quenchants, are tested by Inconel 600 standard probe [4] and currently there is no enough experimental data to perform correct calculations. Author believes that obtained data on effective dimensionless numbers Kn will make PAG solutions ideal quenchants for many high-tech contemporary technologies. For example, low concentration of PAG polymer solutions can be used for performing intensive quenching processes [17-19]. Small concentration (about $1 \%$ ) can eliminate completely film boiling that makes process of cooling intensive since real heat transfer coefficients during nucleate boiling are huge (Table 1) [20].

\section{Table 1}

Influence of the PAG concentration on the duration of film- and nucleate boiling during quenching silver spherical probe $20 \mathrm{~mm}$ in diameter $\left(20^{\circ} \mathrm{C}\right)[20]$.

\begin{tabular}{cccc}
\hline Concentration, $\%$ & $\boldsymbol{\tau}_{\mathrm{FB}}, \mathbf{s}, \mathbf{s}$ & $\mathbf{v}_{\text {max }},{ }^{\circ} \mathbf{C} / \mathbf{s}$ \\
\hline Water & 7 & 2 & 231 \\
PAG, $1 \%$ & 0.2 & 2.1 & 674 \\
3 & 1.5 & 2.5 & 467 \\
10 & 1.8 & 4 & 336 \\
20 & 2.6 & 6 & 251
\end{tabular}

Small concentration creates very thin surface polymeric layer that cannot radically decrease cooling rate of steel parts, however can change radically situation by decreasing initial heat flux density and such a way lowering it below the first critical heat flux density. In this case, instead of film boiling $\left(300-500 \mathrm{~W} / \mathrm{m}^{2} \mathrm{~K}\right)$ will be nucleate boiling $\left(200,000 \mathrm{~W} / \mathrm{m}^{2} \mathrm{~K}\right)$ that provides uniform and intensive cooling. As known, intensification of cooling doesn't affect distortion [10] if quenching is uniform. Investigation of effect of insulating layers on intensity of cooling is a new direction in heat treating industry since it makes processes cheaper, more effective and very simple for implementation. However, prior to be widely used in the practice, additional investigations should be performed concerning kinetics of creation and dissolving polymeric surface layers during quenching. Also, thermal properties of polymeric surface layers should be carefully investigated versus temperature and variation of thickness of insulating layers on the surface of steel parts during quenching should be known. Furthermore, Inconel 600 probe was used for comparison purposes and it cannot be used for evaluating real heat transfer coefficients which are needed for temperature field calculations and residual stresses forming. The best way of such investigation is Liscic probe combined with the video and thermal acoustic technique [21, 22]. Further detail investigations of the 
cooling characteristics of inverse solubility polymers can bring the great benefits for heat treating industry. To have a great success, the software governing cooling processes in PAG polymers should be developed which includes DATABASE of form factors $\mathrm{K}$ for different steel parts, intensity of cooling $\mathrm{Kn}$ for different quenchants and thermal properties of materials to design quickly and correctly recipes for quenching processes preventing crack formation and minimizing distortion. To solve completely the problem, emitters were proposed to use during batch quenching which don't dissolve locally polymeric coatings [23]. And also contemporary approaches, hyperbolic heat conductivity equations taking into account insulating surface layers, should be used to investigate accurately further quenching processes in polymers of inverse solubility [24-28]. Especially, results of investigations are of great value connected with the forms approaching the real steel components [29, 30].

\section{Conclusions}

1. It is shown that during quenching in PAG inverse solubility polymers small temperature gradient is formed in hardened metal and maximal temperature gradient is established in the insulating polymeric layer. This fact opens the new horizons for developing high- tech processes.

2. It has been discovered that local dissolving of insulating surface polymeric layer leads to big distortion of steel parts during quenching in spite of ideal cooling in PAG polymers.

3. To reduce distortion and prevent crack formation during quenching in polymers of inverse solubility it is proposed to interrupt cooling when core temperature approaches martensite start temperature Ms or turn off agitation.

4. The data obtained by testing Inconel 600 probe can be recalculated and used for calculating cooling time for any configuration of steel part if film boiling is absent and intensity of cooling is evaluated by effective dimensionless number $\mathrm{Kn}$.

5. It has been established that low water concentration of PAG polymers (about $1 \%$ ) completely eliminates film boiling even during testing of silver $20 \mathrm{~mm}$ spherical silver probe. It creates big opportunity for intensive quenching processes, namely for IQ-2 process, during batch quenching [20].

7. Author proposes using emitters instead of propellers during batch quenching to eliminate completely local dissolving of PAG polymer layers which are a reason for big distortion of metal components [23].

\section{References}

[1] Totten, G. E., Bates, C. E., Clinton, M. A. (1993). Handbook of Quenchants and Quenching Technology. Materials Park, Ohio: ASM International, 507.

[2] UCON ${ }^{\mathrm{TM}}$ Fluids and Lubricants - Quenchants. The Dow Chemical Company. Available at: http://www.dow.com/ucon/formulated/fluids/quench.htm

[3] The Dow Chemical Company (2015). UCON ${ }^{\mathrm{TM}}$ ULTRAQUENCH ${ }^{\mathrm{TM}}$. A Plus Quenchant. Available at: http://chemtool.com/wp-content/uploads/2015/07/UCON-Ultraquench-A-Plus.pdf

[4] ASTM Standard D6482-99: Standard Test Method for Determination of Cooling Characteristics of Aqueous Polymer Quenchants with Agitation (Tensi Method) (2000). Annual Book of ASTM Standards. West Conshohocken, PA: ASTM International. doi: 10.1520/d6482-99

[5] ASTM Standard D6549-00: Standard Test Method for Determination of Cooling Characteristics of Quenchants by Cooling Curve Analysis with Agitation (Drayton Unit) (2000). Annual Book of ASTM Standards. West Conshohocken, PA: ASTM International. doi: 10.1520/d6549-00

[6] Kobasko, N. I. (2012). Real and Effective Heat Transfer Coefficients (HTCs) Used for Computer Simulation of Transient Nucleate Boiling Processes during Quenching. Materials Performance and Characterization, 1 (1), 104656. doi: 10.1520/mpc104656

[7] Kobasko, N. I. (2016). Self - regulated thermal process, its main characteristics and practical application. International Journal of Current Research, 8 (11), 41698-41704.

[8] Kobasko, N. I., Totten, G. E.; In: Neklyudov, I. M., Shulayev, V. M. (2004). Development Technology of Quenching Processes and Possible Ways of their Intensification. New Heat Treating Processes. Kharkov: Contrast, 93-112.

[9] Kondratjev, G. M. (1957). Thermal Measurements. Moscow: Mashgiz, 244. 
[10] Kobasko, N., Aronov, M., Powell, J., Totten, G. (2010). Intensive Quenching Systems: Engineering and Design. W. Conshohocken, PA, USA: ASTM International, 234. doi: 10.1520/mnl64-eb

[11] Totten, G. E., Liscic, B., Sun, Y. H., Kobasko, N. I., Han, S. W. (1998). Polymer Quenching Technology: An Overview. 11th Congress of the International Federation of Heat Treatment and Surface Engineering - 4th ASM Heat Treatment and Surface Engineering Conference in Europe Proceedings, 1. Florence: AIM-Associazione Italiana di Metallurgia, 141-150.

[12] Totten, G. E., Liscic, B., Sun, Y. H. (1998). Development of Cooling Curve Analysis Standards With Agitation: A Status Report. 11th Congress of the International Federation of Heat Treatment and Surface Engineering - 4th ASM Heat Treatment and Surface Engineering Conference in Europe Proceedings, 1. Florence: AIM-Associazione Italiana di Metallurgia, 171-180.

[13] Lykov, A. V. (1967). Teoriya Teploprovodnosti (Theory of Heat Conductivity). Moscow: Vyschaya Shkola, 596.

[14] Kobasko, N. (2016). Designing of advanced and original austempering processes based on thermal science and engineering physics approaches. EUREKA: Physics and Engineering, 2, 43-50. doi: $10.21303 / 2461-4262.2016 .00060$

[15] Stratton, P. F. (2005). Process Optimization for Deep Cold Treatment of Tool Steels. Proceedings of the $1^{\text {st }}$ International Conference on Heat Treatment and Surface Engineering of Tools and Dies, 11-19.

[16] Bhadeshia, H. K. D. H. (2015). Bainite in Steels: Theory and Practice. Ed. 3. Money Publishing, 616.

[17] Kobasko, N. I., Aronov, M. A., Ferguson, B. L., Li, Z. (2012). Local Film Boiling and Its Impact on Distortion of Spur Gears During Batch Quenching. Materials Performance and Characterization, 1 (1), 104533. doi: 10.1520/mpc104533

[18] Kobasko, N. I., Aronov, M. A. (2014). Intensive Quenching. Comprehensive Materials Processing, 253-269. doi: 10.1016/b978-0-08-096532-1.01208-5

[19] In: Dossett, J., Totten, G. E. (2013). ASM Handbook, Volume 4A, Steel Heat Treating Fundamentals and Processes. Materials Park, Ohio: ASM International, 784.

[20] Moskalenko, A. A., Kobasko, N. I., Tolmacheva, O. V., Totten, G. E., Webster, G. M. (1996). Quechants Characterization by Acoustical Noise Analysis of Cooling Properties of Aqueous Poly (Alkylene Glycol) Polymer Quenchants. Proceedings of the Second International Conference on Quenching and Control of the Distortion, 117-122.

[21] Liscic, B., Filetin, T. (2011). Global Database of Cooling Intensities of Liquid Quenchants. Proceedings of the European Conference on Heat Treatment. Quality in Heat Treatment, 40-49.

[22] Tensi, H. M.,Totten, G. E., Künzel, T. (2000). Physics and Technology of Quenching in Fluids Part I. The 12th IFHTSE Congress Proceedings, 1-4.

[23] Kobasko, N. I. (10.09.2015). Intensive Hardening Method for Metal Components. Patent UA 8357827 C2. Appl. № a 2013 11760. Filed 07.10.2013. Bull. 17. Available at: http://uapatents. com/5-109572-sposib-intensivnogo-gartuvannya-metalevikh-virobiv.html

[24] Buike, M., Buikis, A., Kalis, H. (2015). Wave energy and steel quenching models, which are solved exactly and approximately. Proceedings of the 3rd International Conference on Applied, Numerical and Computational Mathematics (ICANCM'15). Mathematical and Computational Methods in Applied Sciences, 72-81.

[25] Buikis, A., Kalis, H. (2010). Hyperbolic Heat Equation in Bar and Finite Difference Schemes of Exact Spectrum. Latest Trends on Theoretical and Applied Mechanics, Fluid Mechanics and Heat \& Mass Transfer. WSEAS Press, 142-147.

[26] Buike, M., Buikis, A., Kalis, H. (2015). Time Direct and Time Inverse Problems for Wave Energy and Steel Quenching Models, Solved Exactly and Approximately. WSEAS Transactions on Heat and Mass Transfer, 10, 30-43.

[27] Buikis, A., Kalis, H. (2015). Hyperbolic type approximation for the solutions of the hyperbolic heat conduction equation in 3-D domain. Proceedings of the 3rd International Conference on Applied, Numerical and Computational Mathematics ICANCM'15). Mathematical and Computational Methods in Applied Sciences, 42-51.

[28] Blomkalna, S., Buikis, A. (2014). Heat Conduction Problem for Double-Layered Ball. Progress in Industrial Mathematics at ECMI 2012, 417-426. doi: 10.1007/978-3-319-05365-3_58

[29] Bobinska, T., Buike, M., Buikis, A. (2010). Hyperbolic heat equation as mathematical model of steel quenching of L-shape samples. Proceedings of the 5th IASME/WSEAS International Conference on Continuum Mechanics, Fluids, Heat, Cambridge. UK: WSEAS Press, 21-26.

[30] Buikis, A. (2009). Some new models and their solutions for intensive steel quenching. Abstracts of the International Conference Mathematical Modelling and Analysis, 10. doi: 10.13140/RG.2.1.4883.6008 